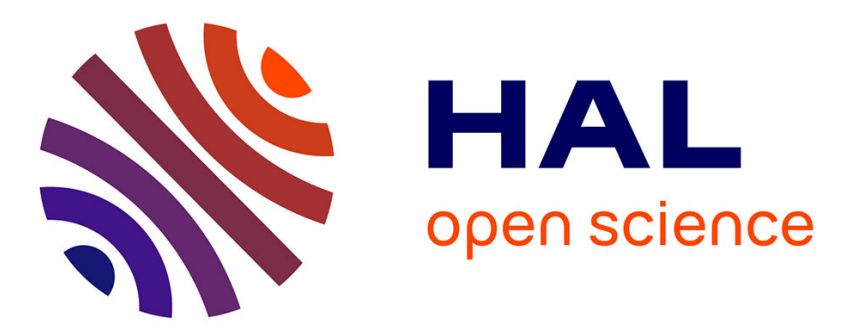

\title{
L'ARN satellite du virus de la mosaïque du concombre IV. - Transmission expérimentale de la maladie nécrotique de la tomate par pucerons
}

Mireille Jacquemond

\section{- To cite this version:}

Mireille Jacquemond. L'ARN satellite du virus de la mosaïque du concombre IV. - Transmission expérimentale de la maladie nécrotique de la tomate par pucerons. Agronomie, 1982, 2 (7), pp.641646. 10.1051/agro:19820707 . hal-02728562

\section{HAL Id: hal-02728562 \\ https://hal.inrae.fr/hal-02728562}

Submitted on 2 Jun 2020

HAL is a multi-disciplinary open access archive for the deposit and dissemination of scientific research documents, whether they are published or not. The documents may come from teaching and research institutions in France or abroad, or from public or private research centers.
L'archive ouverte pluridisciplinaire HAL, est destinée au dépôt et à la diffusion de documents scientifiques de niveau recherche, publiés ou non, émanant des établissements d'enseignement et de recherche français ou étrangers, des laboratoires publics ou privés. 


\title{
L'ARN satellite du virus de la mosaïque du concombre IV. - Transmission expérimentale de la maladie nécrotique de la tomate par pucerons
}

\author{
Mireille JACQUEMOND \\ I.N.R.A., Station de Pathologie végétale, Centre de Recherches d'Avignon, F 84140 Montfavet
}

RÉSUMÉ
Virus de la mosaïque
du concombre,
ARN satellite,
Tomate,
Nécrose,
Transmission
par pucerons,
Aphis gossypii,
Myzus persicae.

Les essais de transmission par pucerons du VMC, additionné de son ARN satellite à forte $(5 \mu \mathrm{g} / \mathrm{ml})$ ou très faible $\left(5 \times 10^{-6} \mu \mathrm{g} / \mathrm{ml}\right)$ concentration, à la tomate ont conduit aux conclusions suivantes :

1) Il n'existe pas de proportionnalité entre le taux de transmission assuré à partir d'une plante et sa concentration en particules virales infectieuses. L'espèce hôte joue par contre un rôle plus important au niveau de son efficacité comme source de virus. Ainsi, le melon constitue une source aussi efficace pour l'acquisition du VMC par les pucerons que la tomate ou le tabac bien qu'il soit moins favorable à la multiplication du virus.

2) La possibilité de transmission de l'ARN satellite avec les ARN du génome est liée à sa concentration dans les particules virales. Il est toujours transmis par les pucerons lorsqu'il a été abondamment répliqué dans la plante source (tomate ou tabac, 45 à $50 \mathrm{p}$. 100 de l'ARN viral encapsidé). Les tomates contaminées développent alors uniquement le syndrome nécrotique. Par contre, il peut ne pas être transmis s'il ne représente que 15 p. 100 environ de l'ARN viral encapsidé, puisquc les tomates infectées extériorisent parfois les symptômes de filiformisme grave, caractéristiques de l'absence de réplication de l'ARN satellite nécrogène. Dans ce cas, les résultats diffèrent de ceux obtenus, à partir des mêmes sources, par transmission mécanique.

3) Lorsque la plante source de virus est riche en ARN satellite, son efficacité pour l'acquisition du virus par les aphides paraît nettement réduite.

4) Des tomates âgées de 30 à $40 \mathrm{j}$, stade auquel elles sont généralement repiquées au champ, sont toujours très sensibles à l'inoculation par pucerons.

\section{SUMMARY}

\section{Cucumber}

mosaic virus,

Satellite RNA

Tomato,

Necrosis,

Aphid transmission,

Aphis gossypii,

Myzus persicae.
Cucumber mosaic virus associated RNA-5. IV. - Experimental transmission of the tomato necrosis by aphids.

Experiments of aphid transmission of CMV, with satellite RNA added at high $(5 \mu \mathrm{g} / \mathrm{ml})$ or very low $\left(5 \times 10^{-6} \mu \mathrm{g} / \mathrm{ml}\right)$ concentration, to tomato plants lead us to the following conclusions :

(1) The transmission rate from a source plant is not directly correlated with its virus concentration. However, the transmission rate is dependent on the host species. So, muskmelon seems to be a better source than tomato or tobacco, although it is a less efficient host for virus multiplication.

2) The possibility of transmission of the satellite RNA, with the genomic RNAs, is associated with its concentration in the particles synthetized in the source. RNA-5 is always transmitted by aphids when it represents a great proportion of the viral RNA (tomato or tobacco as source plants, 45 to 50 per cent of RNA-5). So infected tomato plants only display necrosis. Nevertheless, RNA-5 may be not transmitted when it is produced in lower proportion in the source (muskmelon, 15 per cent of the viral RNA) since the inoculated tomato plants sometimes show mosaic and fern leaf symptoms, characteristic of the absence of replication of the satellite RNA. These last results differ from those obtained, with the same source, by mechanical inoculation.

3) A host plant in which satellite RNA has been actively replicated is a less efficient source for aphids than one containing a small amount of it.

4) Tomato plants, when 30 to 40 days old, stage of development to which they are usually transplanted in the field, are still very susceptible to CMV inoculation by aphids.

\section{INTRODUCTION}

Le virus de la mosaïque du concombre (VMC) est, parmi les virus qui infectent les cultures de tomates du sud-est de la France, le plus fréquent (QUIOT et al., 1979a). Chez cet hôte, le VMC induit 2 types de symptômes: une mosaïque associée à une réduction de la surface foliaire plus ou moins accentuée (filiformisme) ou une nécrose létale. 
Le syndrome nécrotique est associé à la présence, dans les particules virales, de l'ARN-5 (ARN satellite) de type D (KAPER \& WATERWORTH, 1977 ; JACQUEMOND \& LOT, 1981). Le développement de mosaïque et de filiformisme correspond à l'infection par le virus dépourvu d'ARN satellite ou porteur d'ARN-5 de type $R$, non nécrogène (JACQUEMOND \& LOT, 1981).

Les cultures sensibles au virus (les Cucurbitacées en particulier) ainsi que de nombreuses plantes sauvages constituent les principales sources de VMC au champ (QUIOT et al., 1979b, 1979c). Ces diverses espèces peuvent héberger des populations virales aptes ou non à induire le syndrome nécrotique létal chez la tomate (LECOQ \& JACQUEMOND, résultats non publiés).

L'étude du développement des épidémies de VMC, dans les cultures de tomates de notre région, a montré que les 2 maladies évoluent au champ indépendamment l'une de l'autre. Elles se caractérisent par leur mode de répartition, aléatoire dans le cas de mosaïque et de filiformisme, en foyers épidémiques pour la nécrose (QUIOT et al., 1979d).

Le VMC est transmis par aphides selon le mode non persistant. Deux espèces de pucerons sont principalement impliquées dans la dissémination du virus dans notre région: Aphis gossypii Glov. et Myzus persicae Sulz. (LeClant \& MESSiaEN, 1965).

Les travaux dont les résultats sont présentés ici avaient pour but d'étudier la transmission, par ces vecteurs, de l'ARN satellite associé au génome viral et donc, de définir quelques paramètres pouvant intervenir dans la dissémination naturelle des 2 types de maladies provoquées par le VMC chez la tomate. Ils ont permis de préciser l'incidence de la présence de l'ARN-5 dans les particules virales synthétisées chez plusieurs espèces sur l'efficacité de ces hôtes comme sources pour l'acquisition du VMC et sur le faciès de la maladie transmise.

\section{MATÉRIEL ET MÉTHODES}

\section{A. Les souches de virus}

Les souches $I_{17} F$ et $I_{17} N$ sont issues d'un même isolat de VMC, prélevé sur une tomate (Lycopersicon esculentum Mill.) de plein champ atteinte de mosaique, par transferts successifs d'une lésion locale sur Vigna sinensis (L.) Endl. Les méthodes de purification du virus et des ARN ainsi que les méthodes d'inoculation mécanique ont été décrites précédemment (JACQUEMOND \& LOT, 1981).

Deux inoculums ont été choisis pour ces essais :

- ARN de la souche $I_{17} F(20 \mu \mathrm{g} / \mathrm{ml})$ - dépourvu d'ARN satellite et inducteur de mosaïque et de filiformisme grave chez la tomate - additionné de l'ARN-5 purifié à partir de la souche $I_{17} \mathrm{~N}(5 \mu \mathrm{g} / \mathrm{ml})$. Lorsque cet inoculum est propagé chez la tomate ou le tabac (Nicotiana tabacum $\mathrm{L}$. cv. "Xanthi nc. "), l'ARN-5 représente 45 à 50 p. 100 de l'ARN viral encapsidé. Les tomates développent le syndrome nécrotique. Lorsqu'il est propagé chez le melon (Cucumis melo L. cv. "Cantaloup Charentais)" la proportion relative d'ARN-5 dans les nucléoprotéines est de 15 p. 100 environ (JACQUEMOND \& LEROUX, 1982).

- ARN de la souche $\mathrm{I}_{17} \mathrm{~F}(20 \mu \mathrm{g} / \mathrm{ml})$ additionné de l'ARN-5 $I_{17} \mathrm{~N}$ à une dose extrêmement réduite $\left(5 \times 10^{-6} \mu \mathrm{g} / \mathrm{ml}\right)$. La réplication de l'ARN satellite est, dans ces conditions, assurée de façon variable selon l'hôte : fréquemment chez le tabac, plus rarement chez la tomate et surtout le melon (JACQUEMOND \& LEROUX, 1982).

\section{B. Les plantes sources}

Les plantes servant à l'acquisition du virus par les pucerons - ou plantes sources - sont maintenues, avant et après infection, dans un compartiment de serre «insectproof " dont la température est régulée $\left(16-17^{\circ} \mathrm{C}\right.$ durant la nuit et $23-24^{\circ} \mathrm{C}$ durant le jour), équipé d'un dispositif de lumière additionnelle afin d'assurer $16 \mathrm{~h}$ de jour.

Afin d'éviter les variations d'efficacité des sources de virus liées à la durée d'incubation (STIMMANN \& SWENSON, 1967 ; LECOQ et al., 1979), les plantes sont toujours utilisées $7 \mathrm{j}$ après la contamination dans le cas des melons et des tabacs, $12 \mathrm{j}$ pour les tomates.

\section{Méthode de transmission}

Les colonies d' $A$. gossypii et de $M$. persicae sont respectivement maintenues sur melons et piments (Capsicum annuum L. cv. "Yolo Wonder»). Les conditions d'élevage déterminées par LECOQ et al. (1979) permettent l'obtention de populations homogènes d'A. gossypii. Les pucerons utilisés pour les essais de transmission sont des adultes. Par contre, dans le cas de $M$. persicae, il y a, outre des adultes, quelques larves de dernier stade. La technique d'inoculation a été décrite par LECOQ et al. (1979).

Les tomates utilisées comme plantes tests (cv. "Monalbo ») sont cultivées dans les mêmes conditions que les plantes sources. Pour chaque traitement, 10 plantes sont inoculées par les pucerons sur les cotylédons. Chaque expérience a été réalisée 3 fois, sauf indication contraire. Les résultats présentés correspondent aux moyennes des valeurs obtenues au cours de ces 3 répétitions.

\section{Contrôle des sources de virus}

Le pouvoir infectieux spécifique du virus synthétisé chez les diverses plantes sources est déterminé, à la fin de chaque expérience, en inoculant un extrait à la dilution adéquate sur une feuille de 10 jeunes $V$. sinensis. Les lésions locales sont dénombrées $48 \mathrm{~h}$ plus tard. La moyenne de ces 10 valeurs caractérise le potentiel infectieux de la source.

Les propriétés pathogènes du virus chez la tomate sont également déterminées par inoculation mécanique d'un extrait brut à 10 plantes.

Les résultats présentés correspondent aux moyennes établies pour les 3 expérimentations successives.

\section{RÉSULTATS}

\section{A. Influence de la concentration de l'ARN-5 dans l'inocu- lum sur les taux de transmission et le faciès de la maladie transmise}

\section{Taux de transmission}

Des nombres croissants de pucerons (A. gossypii ou $M$. persicae) ayant acquis le virus sur des melons infectés par les inoculums contenant des traces ou $5 \mu \mathrm{g} / \mathrm{ml}$ d'ARN satellite, ont été déposés par plante test. Les taux de transmission obtenus sont reportés sur la figure 1. Les probabilités estimées de transmission de chaque inoculum par 1 puceron 


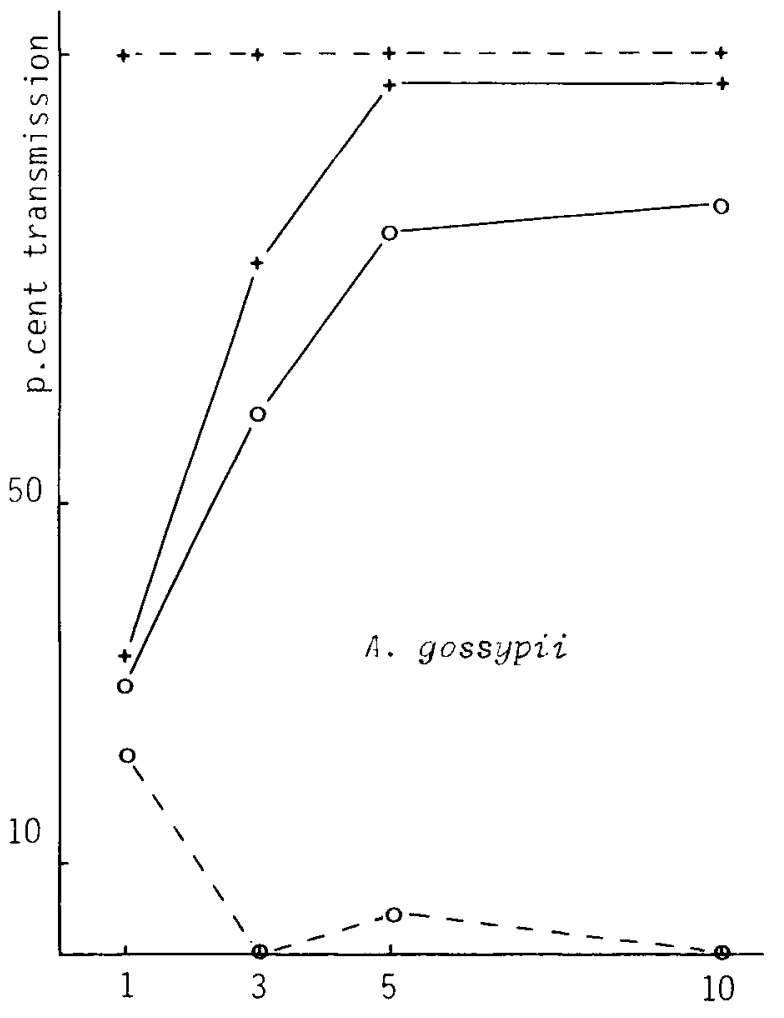

Figure 1

Pourcentages de tomates infectées par le VMC (-) et développant des symptômes de filiformisme (--) après leur contamination à l'aide d'A. gossypii ou de M. persicae ayant acquis le virus sur des melons infectés par les inoculums contenant $5 \times 10^{-6} \mathrm{\mu g} / \mathrm{ml} \mathrm{(+)} \mathrm{ou}$ $5 \mu \mathrm{g} / \mathrm{ml}(\mathrm{O})$ d'ARN satellite.

de chaque espèce ont été calculées selon la formule donnée par GIBBS \& Gower (1960) :

$\mathrm{P}^{*}=1-\left(1-\frac{\mathrm{R}}{\mathrm{N}}\right)^{1 / \mathrm{i}}$

$\mathrm{R}$ : nombre de tomates infectées ;

$\mathrm{N}$ : nombre de tomates éprouvées ;

i : nombre de pucerons déposés par plante test.

Les 2 séries de probabilités, correspondant aux 2 inoculums, ont été comparées, pour chaque espèce vectrice, par le test des rangs (WILCOXSON). Cette analyse montre que l'inoculum contenant des traces d'ARN-5 est sensiblement mieux transmis que l'inoculum pourvu d'une quantité abondante d'ARN-5 (niveau de signification 0,05) et cela quelle que soit l'espèce vectrice.

La présence d'ARN satellite en concentration élevée dans l'inoculum provoque une importante réduction de la synthèse virale (JACQUEMOND \& LEROUX, 1982). Cela explique la différence des potentiels infectieux des 2 sources utilisées (rapports égaux à 3,4 et 4 pour chaque série d'essais, tabl. 1). Or, les taux de transmission assurés à partir de ces sources ne varient pas dans des rapports aussi élevés (fig. 1). Il semble donc qu'il n'y ait pas de proportionnalité entre la teneur d'une plante en particules virales infectieuses et son efficacité comme source de virus pour les aphides.

\section{Faciès de la maladie transmise}

La synthèse de l'ARN-5 présent à la dose de $5 \times 10^{-6} \mu \mathrm{g} / \mathrm{ml}$ dans l'inoculum est aléatoire. En effet, le

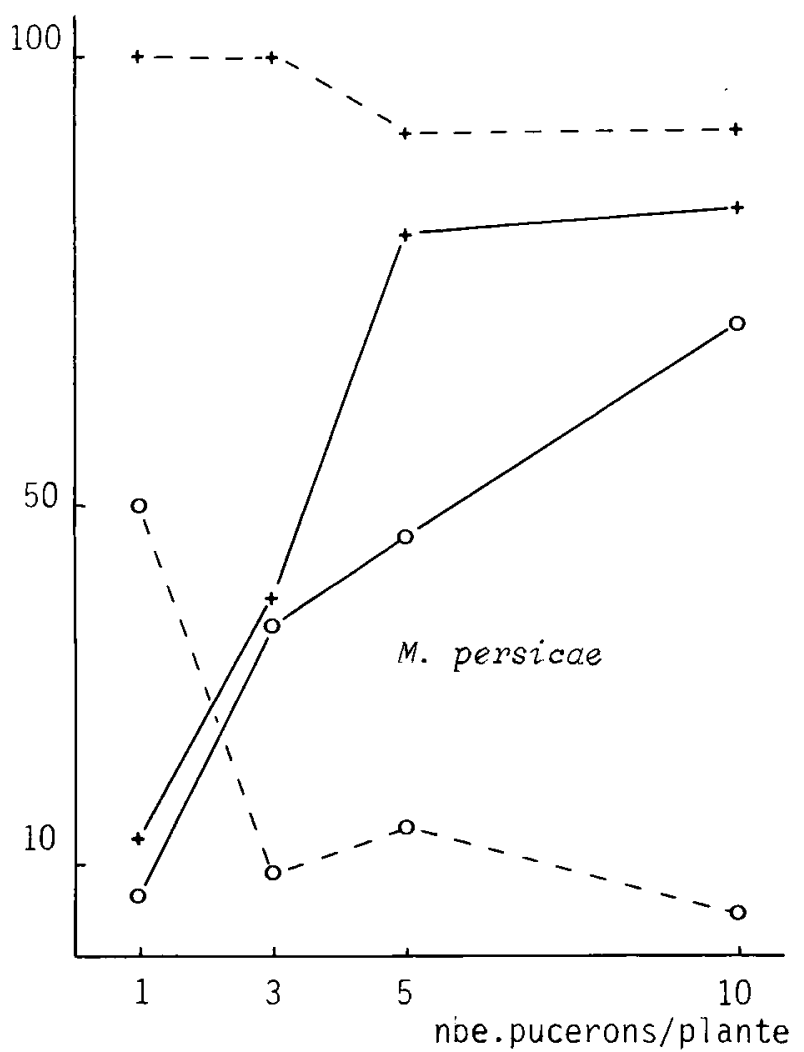

Proportions of tomato plants infected by $\mathrm{CMV} \mathrm{(-)} \mathrm{and} \mathrm{displaying}$ fern leaf symptoms (--) after contamination with A. gossypii or M. persicae. Virus sources were muskmelons infected with inocula containing $5 \times 10^{-6} \mu \mathrm{g} / \mathrm{ml}(+)$ or $5 \mu \mathrm{g} / \mathrm{ml}(\mathrm{O}) \mathrm{RNA}-5$.

\section{TABLEAU 1}

Caractéristiques des sources de virus (melons) utilisées pour la transmission du VMC à la tomate par A. gossypii et M. persicae. Characteristics of virus sources (muskmelons) used in transmission experiments of CMV to tomato plants by $\mathrm{A}$. gossypii and M. persicae.

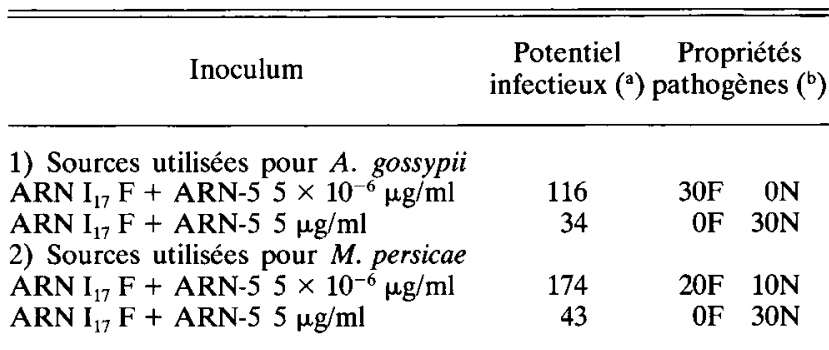

(a) Nombre moyen de lésions locales développées par feuille de $V$. sinensis infectée au moyen de l'extrait des sources dilué au 1/500. (Mean number of local lesions produced per leaf of $V$. sinensis inoculated with diluted sap $(1 / 500)$ from sources leaves.)

(b) Nombre de tomates présentant les symptômes de filiformisme $(\mathrm{F})$ ou de nécrose $(\mathrm{N})$ après leur contamination par un extrait brut des sources. (Number of tomato plants displaying fern leaf symptoms (F) or necrosis $(\mathrm{N})$ after infection by the crude extract from sources leaves.)

contrôle des propriétés pathogènes des sources (tabl. 1) montre que cette synthèse n'a pas été assurée chez les melons utilisés comme sources de virus pour $A$. gossypii. Les pucerons ont, dans ce cas, transmis uniquement la maladie de filiformisme (fig. 1). Par contre, au cours des 
essais réalisés avec $M$. persicae, l'ARN-5 a été faiblement répliqué puisque le tiers des tomates inoculées mécaniquement avec l'extrait brut des melons sources ont développé le syndrome nécrotique (tabl. 1). Les pucerons ont alors transmis la nécrose, mais à un taux faible, et seulement lorsque leur nombre était supérieur à 3 par plante test (fig. 1)

Bien qu'ayant acquis le virus sur des melons où l'ARN-5, apporté à une dose élevée $(5 \mu \mathrm{g} / \mathrm{ml})$ dans l'inoculum, a été produit en quantité relativement importante $(15$ p. 100 de l'ARN total encapsidé), les pucerons des 2 espèces peuvent transmettre la maladie de filiformisme (fig. 1). La fréquence relative de ce symptôme tend à diminuer lorsque le nombre de pucerons virulifères déposés par plante test augmente. Par contre, l'inoculation mécanique de l'extrait brut de ces sources a toujours conduit au développement du seul syndrome nécrotique chez les tomates (tabl. 1).

\section{B. Efficacité de la tomate et du tabac comme sources de virus pour A. gossypii}

La tomate et le tabac assurent la multiplication du virus avec des efficacités différentes. En effet, la teneur des particules virales infectieuses est beaucoup plus forte (de l'ordre de 3,5 fois) chez la tomate que chez le tabac lorsque ces hôtes sont contaminés par un inoculum très faiblement porteur d'ARN satellite. Pourtant, les taux de transmission par pucerons varient peu (tabl. 2). L'espèce utilisée comme source de virus par les pucerons paraît être un paramètre important. Ceci est confirmé par les taux de transmission quelque peu plus élevés observés lorsque la source de virus est le melon infecté dans les mêmes conditions (33,3 et 76,5 p. 100 lorsque 1 et 3 pucerons respectivement sont déposés par plante test, fig. 1), alors que cet hôte est moins favorable à la multiplication virale (tabl. 1).

L'ARN-5 peut représenter 10 p. 100 de l'ARN synthétisé chez les tomates ou les tabacs contaminés au moyen de l'inoculum contenant $5 \times 10^{-6} \mu \mathrm{g} / \mathrm{ml}$ d'ARN satellite (JACQUEMOND \& LEROUX, 1982). C'est pourquoi les 2 faciès maladifs peuvent apparaître lorsque ces hôtes ainsi infectés constituent les sources de virus. Cependant, la fréquence des tomates extériorisant les symptômes de mosaïque et de filiformisme est plus grande lorsque la transmission est assurée par pucerons que lorsqu'elle est assurée par voie mécanique (tabl. 2). Par contre, lorsque l'ARN-5 est abondamment produit dans la plante source (inoculum en contenant $5 \mu \mathrm{g} / \mathrm{ml}$ ), seule la nécrose est transmise, quel que soit le procédé d'inoculation (tabl. 2).

Comme chez le melon, la présence d'ARN satellite à une dose élevée dans l'inoculum induit une réduction considérable de la synthèse virale. En effet, les concentrations des particules virales infectieuses varient dans un rapport de 6,2 chez la tomate et 2,3 chez le tabac. Mais, dans ces 2 cas, les taux de transmission par 1 ou 3 pucerons subissent également une réduction très sensible (facteurs de 4 et 2 respectivement). Il semble donc que la présence d'ARN-5, en proportion aussi élevée dans les particules, soit en partie responsable de la perte d'efficacité de la tomate et du tabac comme sources de virus.

\section{Sensibilité de tomates à différents stades de développe- ment}

Les tomates sont très sensibles à l'inoculation par pucerons lorsqu'elles sont au stade plantule. Par contre, leur sensibilité semble quelque peu réduite lorsqu'elles atteignent le stade premier bouquet floral bien que les taux de transmission observés soient encore très élevés (tabl. 3 ). Ces résultats ne confirment pas les observations antérieures de MESSIAEN et al. (1963) qui estimaient que des plantes âgées de $30 \mathrm{j}$ sont pratiquement résistantes à l'inoculation par 10 pucerons (A. gossypii). Toutefois, ceci peut être attribué à des différences de conditions expérimentales, ces auteurs ayant décrit des taux de transmission, à de plus jeunes tomates, plus faibles que ceux que nous avons observés, ou à l'utilisation de cultivars différents.

\section{DISCUSSION}

L'efficacité de la transmission du VMC par pucerons à la tomate est fonction de plusieurs paramètres parmi lesquels la concentration relative en particules infectieuses ne paraît

\section{TABLEAU 2}

Etude comparée de l'efficacité de la tomate et du tabac infectés par les deux inoculums comme sources de virus pour A. gossypii. Comparative study of the efficiency of tomato and tobacco plants infected by the two inocula as sources of virus for A. gossypii.

\begin{tabular}{|c|c|c|c|c|c|c|c|c|c|c|c|c|c|}
\hline \multirow{3}{*}{$\begin{array}{c}\text { Espèce } \\
\text { source } \\
\text { de } \\
\text { virus }\end{array}$} & \multirow{3}{*}{$\begin{array}{c}\text { Concentration } \\
\text { de l'ARN-5 } \\
\text { dans } \\
\text { l'inoculum } \\
5 \times 10^{-6} \mu \mathrm{g} / \mathrm{ml} \\
5 \mu \mathrm{g} / \mathrm{ml}\end{array}$} & \multicolumn{2}{|c|}{ Dosage } & \multirow{2}{*}{\multicolumn{2}{|c|}{$\begin{array}{c}\text { Propriétés } \\
\text { pathogènes }\left({ }^{b}\right)\end{array}$}} & \multicolumn{6}{|c|}{$\begin{array}{l}\text { Faciès maladif }\left({ }^{c}\right) \text { développé par } \\
\text { des tomates infectées à l'aide de }\end{array}$} & \multicolumn{2}{|c|}{$\begin{array}{l}\text { Taux moyen de } \\
\text { transmission assuré par }\end{array}$} \\
\hline & & Dilution & Potentiel & & & & puce & & & pucer & & 1 puceron & 3 pucerons \\
\hline & & $\begin{array}{r}2000 \\
500\end{array}$ & $\begin{array}{l}567 \\
363\end{array}$ & $\begin{aligned} 10 \mathrm{~F} \\
0 \mathrm{~F}\end{aligned}$ & $\begin{array}{l}20 \mathrm{~N} \\
30 \mathrm{~N}\end{array}$ & $3 F$ & $\begin{array}{l}1 \mathrm{~N} \\
1 \mathrm{~N}\end{array}$ & $\begin{array}{l}16: 0 \\
19: 0\end{array}$ & $20 \mathrm{~F}$ & $10 \mathrm{~N}$ & $\begin{array}{l}10: 0 \\
20: 0\end{array}$ & $\begin{array}{r}20,0 \\
5,0\end{array}$ & $\begin{array}{l}66,7 \\
33,7\end{array}$ \\
\hline Tabac & $\begin{array}{c}5 \times 10^{-6} \mu \mathrm{g} / \mathrm{ml} \\
5 \mu \mathrm{g} / \mathrm{ml}\end{array}$ & $\begin{array}{r}1000 \\
500\end{array}$ & $\begin{array}{l}327 \\
283\end{array}$ & $\begin{array}{l}0 \mathrm{~F} \\
\mathrm{OF}\end{array}$ & $\begin{array}{l}30 \mathrm{~N} \\
30 \mathrm{~N}\end{array}$ & $1 \mathrm{~F}$ & $\begin{array}{l}3 \mathrm{~N} \\
1 \mathrm{~N}\end{array}$ & $\begin{array}{l}16: 0 \\
19: 0\end{array}$ & $4 \mathrm{~F}$ & $\begin{array}{l}12 \mathrm{~N} \\
8 \mathrm{~N}\end{array}$ & $\begin{array}{l}14: 0 \\
22: 0\end{array}$ & $\begin{array}{r}20,0 \\
5,0\end{array}$ & $\begin{array}{l}53,3 \\
26,7\end{array}$ \\
\hline
\end{tabular}

( $\left.{ }^{a}\right)$ Nombre moyen de lésions locales développées par feuille de $V$. sinensis infectée par l'extrait dilué des feuilles. (Mean number of local lesions produced, by rubbing diluted sap from sources leaves, on a leaf of $V$. sinensis.)

$\left({ }^{b}\right)$ Nombre de tomates présentant les symptômes de filiformisme (F) ou de nécrose (N) après leur infection par un extrait brult des sources de virus. (Number of tomato plants displaying fern leaf symptoms (F) or necrosis (N) after infection by a crude extract from sources leaves.)

(c) $20(2 \times 10)$ ou $30(3 \times 10)$ tómates ont été respectivement inoculécs à l'aide de 1 ou 3 pucerons et ont développé des symptômes de filiformisme $(\mathrm{F})$, de nécrose $(\mathrm{N})$, ou n'ont pas extériorisé de symptômes $(0)$. $(20(2 \times 10)$ or $30(3 \times 10)$ tomato plants were respectively inoculated with 1 or 3 aphids and developed fern leaf symptoms $(\mathrm{F})$, necrosis $(\mathrm{N})$, or did not displayed any symptom (0).) 
TABLEAU 3

Sensibilité de tomates à différents stades de développement à la transmission du VMC par pucerons $\left({ }^{a}\right)$.

Susceptibility of tomato plants of different stages of development to the transmission of $C M V$ by aphids $\left(^{a}\right)$.

\begin{tabular}{cccc}
\hline \hline Exp. & $\begin{array}{c}\text { Age des } \\
\text { tomates } \\
\text { (jours) }\end{array}$ & $\begin{array}{c}\text { Nombre } \\
\text { de feuilles } \\
\text { développées }\end{array}$ & $\begin{array}{c}\% \\
\text { de plantes } \\
\text { infectées }\end{array}$ \\
\hline \multirow{2}{*}{1} & 15 & 2 & 100 \\
& 21 & 5 & 100 \\
& 22 & 5 & 100 \\
& 29 & 7 & 100 \\
& 33 & 9 & 100 \\
2 & 36 & $9+\mathrm{BF}\left(^{b}\right)$ & 80 \\
& 15 & 2 & 100 \\
& 21 & 5 & 100 \\
& 23 & 6 & 100 \\
& 25 & 8 & 100 \\
& 32 & 9 & 80 \\
& 34 & $9+\mathrm{BF}\left({ }_{b}\right)$ & 60
\end{tabular}

(a) La plante source est le melon infecté par l'ARN $\mathrm{I}_{17} \mathrm{~F}$ additionné d'ARN-5 à la dose de $5 \times 10^{-6} \mu \mathrm{g} / \mathrm{ml}$. La transmission est assurée par $A$. gossypii à raison de 10 pucerons virulifères par plante test. (Virus source is muskmelon infected by $\mathrm{I}_{17} \mathrm{~F}$ RNA with RNA-5 added at $5 \times 10^{-6} \mu \mathrm{g} / \mathrm{ml}$. 10 viruliferous aphids $(A$. gossypii) were deposited on each test plant.)

(b) Premier bouquet floral. (First inflorescence.)

pas jouer un rôle essentiel. GERA et al. (1979) avaient également rapporté l'absence de proportionnalité entre la teneur en particules virales infectieuses d'une source et son efficacité pour l'acquisition du virus par $A$. gossypii.

Le taux de transmission d'un même isolat est, par contre, dépendant de l'espèce utilisée comme source de virus. En effet, bien que présentant des concentrations virales faibles comparativement à la tomate ou au tabac, le melon a constitué, au cours de nos essais, une source au moins aussi efficace. Ces différences s'accentuent lorsque la durée d'incubation des sources est prolongée (QUIOT et al., $1979 b$ ).

Cependant, des réductions des taux de transmission ont $\mathrm{pu}$ être associées à la présence de l'ARN satellite en concentration élevée dans l'inoculum. Ces réductions, peu sensibles lorsque le melon - hôte moyennement favorable à la synthèse de l'ARN-5 - est utilisé comme source de virus, apparaissent clairement lorsque la tomate ou le tabac - hôtes très favorables à la réplication de l'ARN-5 servent à l'acquisition du virus par les pucerons. On peut supposer que, dans ce cas, l'ARN-5 est apporté seul - ou avec les $A R N$ du génome en concentration trop faible pour initier l'infection - et constitue de ce fait un «inoculum non infecticux ». Cette hypothèse revêt une certaine importance si l'on considère que l'ARN-5 est doté de la propriété de survie (JACOUEMOND \& LOT, 1982). Il peut en effet rester biologiquement actif plusieurs jours après avoir été apporté à une plante où il ne se réplique pas de façon autonome. La relation virus-ARN satellite ne présentant pas de spécificité (JACQUEMOND \& LEROUX, 1982), sa synthèse pourrait alors être initiée au cours d'une infection ultérieure.

Des tomates nécrosées ou en voie de nécrose peuvent être de mauvaises sources de virus au champ, et cela à double titre :

- elles permettent des taux de transmission faibles comparativement aux melons, ou aux tomates atteintes de mosaïque et de filiformisme,

- elles constituent des sources de moindre appétence pour les pucerons (QUIOT et al., 1979d).

La possibilité de transmission par pucerons de la maladie de filiformisme à partir d'une source où l'ARN-5 a été répliqué semble liée à la teneur relative de l'ARN satellite dans les particules virales. Cette éventualité ne s'est en effet présentée que lorsque la proportion d'ARN-5 dans les particules était, au maximum, de l'ordre de 15 p. 100 (melons infectés par l'inoculum riche en ARN satellite, tomates ou tabacs infectés par l'inoculum porteur de traces d'ARN-5). Cela suggère que, dans certains cas, l'ARN-5 peut ne pas être transmis avec les ARN du génome, ou en quantité trop faible pour que sa réplication soit assurée. De ce fait, lorsque le nombre de pucerons virulifères déposés par plante test est plus important, la proportion de plantes présentant les symptômes de filiformisme est plus faible.

Sur le plan épidémiologique, la conséquence de cette donnée est importante. Il apparaît en effet que le faciès de la maladie transmise n'est pas obligatoirement conforme à celui que l'on pourrait attendre compte tenu des potentialités intrinsèques de l'inoculum. Des nucléocapsides pourvues d'ARN satellite, mais en concentration trop faible pour être répliqué, peuvent être transmises, au champ, à partir de certaines espèces pourtant infectées par un isolat nécrogène.

Sur le plan expérimental, ce résultat met en évidence l'importance du mode d'inoculation. La transmission mécanique assure l'apport d'un inoculum homogène, celui-ci étant constitué de solutions purifiées d'ARN. Elle nous a permis de déterminer la dose de $5 \times 10^{-4} \mu \mathrm{g} / \mathrm{ml}$ d'ARN-5 dans l'inoculum comme celle qui est suffisante pour que sa réplication soit optimale quel que soit l'hôte considéré («dose minimale ») (JACQUEMOND \& LEROUX, 1982). Par contre, les inoculums prélevés par différents pucerons doivent être qualitativement différents, puisque l'ARN satellite peut ne pas être transmis avec les ARN du génome alors qu'il représente une proportion non négligeable du contenu nucléique des particules. Ces variations qualitatives peuvent avoir plusieurs origines parmi lesquelles :

- les 3 types de particules du VMC (LOT \& KAPER, 1976) sont diversement répartis dans les cellules infectées,

- l'ARN-5 n'est pas uniformément réparti dans ces particules. L'existence de particules ne contenant que l'ARN satellite peut également être envisagée.

Les tomates, cultivées en pépinières, sont généralement repiquées au champ à l'âge de 30 à $40 \mathrm{j}$. Les taux d'infection par pucerons que nous avons constatés pour des plantes de plus de $30 \mathrm{j}$ sont encore très élevés et expliquent le développement rapide d'épidémies dans les cultures. Ces épidémies peuvent être d'autant plus graves que certaines cultures sont mises en place à des périodes de l'année où les vols de pucerons sont très denses.

Reçu le 3 décembre 1981 Accepté le 2 avril 1982.

\section{REMERCIEMENTS}

L'auteur remercie Hervé LECOQ qui lui a fait bénéficier de ses méthodes d'élevage de pucerons et de transmission. 


\section{RÉFÉRENCES BIBLIOGRAPHIQUES}

Gera A., Loebeinstein G., Raccah B., 1979. Protein coats of two strains of cucumber mosaic virus affect transmission by Aphis gossypii. Phytopathology, 69, 396-399.

Gibbs A. J., Gower J. C., 1960. The use of a multiple-transfer method in plant virus transmission studies. Some statistical points arising in the analysis of results. Ann. appl. Biol., 48 (1), 75-83.

Jacquemond Mireille, Leroux J. P., 1982. L'ARN satellite du virus de la mosaique du concombre. II. Etude de la relation virus-ARN satellite chez divers hôtes. Agronomie, 2 (1), 55-62.

Jacquemond Mireille, Lot H., 1981. L'ARN satellite du virus de la mosaïque du concombre. I. Comparaison de l'aptitude à induire la nécrose de la tomate d'ARN satellites isolés de plusieurs souches du virus. Agronomie, 1 (10), 927-932.

Jacquemond Mireille, Lot H., 1982. L'ARN satellite du virus de la mosaïque du concombre. III. La propriété de survie in vivo. Agronomie, 2, 6 (sous presse).

Kaper J. M., Waterworth H. E., 1977. Cucumber mosaic virus associated RNA-5 causal agent for tomato necrosis. Science, 196, 429-431.

Leclant F., Messiaen C. M., 1965. Contribution à l'étude de l'épidémiologie du virus 1 du concombre dans le sud-est de la

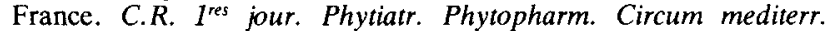
(Abstract), p. 194.

Lecoq H., Cohen S., Pitrat M., Labonne G., 1979. Resistance to cucumber mosaic virus transmission by aphids in Cucumis melo. Phytopathology, 69, 1223-1225.
Lot H., Kaper J. M., 1976. Further studies on the R.NA component distribution among the nucleoproteins of cucumber mosaic virus. Virology, 74, 223-226.

Messiaen C. M., Maison P., Migliori A., 1963. Le virus $1 \mathrm{du}$ concombre dans le sud-est de la France. Phytopath. mediterr., 11, 251-260.

Quiot J. B., Douine Laurence, Gebre Selassie K., 1979a. Fréquence des principales viroses identifiées dans une exploitation maraîchère du sud-est de la France. Ann. Phytopathol., 11 (3), 283-290.

Quiot J. B., Devergne J. C., Cardin L., Verbrugghe M., Marchoux G., Labonne G., 1979b. Ecologie et épidémiologie du virus de la mosaïque du concombre dans le sud-est de la France. VII. Répartition de deux types de populations virales dans des cultures sensibles. Ann. Phytopathol., 11 (3), 359-374.

Quiot J. B., Devergne J. C., Marchoux G., Cardin L., Douine Laurence, $1979 c$. Ecologie et épidémiologie du virus de la mosaïque du concombre dans le sud-est de la France. VI. Conservation de deux types de populations virales dans les plantes sauvages. Ann. Phytopathol., 11 (3), 349-358.

Quiot J. B., Leroux J. P., Labonne G., Renoust M., 1979d. Epidémiologie de la maladie filiforme et de la nécrose de la tomate provoquées par le virus de la mosaïque du concombre dans le sudest de la France. Ann. Phytopathol., 11 (3), 393-408.

Stimmann M. W., Swenson K. G., 1967. Aphid transmission of cucumber mosaic virus affected by temperature and age of infection in diseased plants. Phytopathology, 57, 1074-1076. 